\title{
Factors involved in memory encoding and their implications for the memory performance of older adults and people with mild cognitive impairment ${ }^{*}$
}

\author{
Michael C. C. Kuo ${ }^{1}$, Karen P. Y. Liu ${ }^{2 \#}$, Chetwyn C. H. Chan ${ }^{1}$ \\ ${ }^{1}$ Department of Rehabilitation Sciences, The Hong Kong Polytechnic University, Hong Kong, China \\ ${ }^{2}$ School of Science and Health, University of Western Sydney, Sydney, Australia \\ Email: "Karen.Liu@uws.edu.au
}

Received 27 January 2012; revised 4 March 2012; accepted 21 March 2012

\begin{abstract}
Rehabilitation of episodic memory declines typically focuses on alleviating the demand for recall and improving the retrieval process. Modulating the encoding is not commonly practiced, but may nevertheless be important. Seventeen event-related potential (ERP) studies interpreted using the subsequent memory effect, an index of successful encoding, are reviewed and the factors involved in encoding are discussed. The nature of the materials used for testing, modes of encoding, and the nature of the retrieval task are highlighted as important factors. Meaningful materials and processing information semantically enhance encoding to episodic memory. The studies reviewed reveal that older persons process information more uniformly without elaboration compared with their younger counterparts. Although people with mild cognitive impairment have encoding and retrieval deficits, an elaborative type of encoding training that draws on successful encoding factors may help to improve memory performance.
\end{abstract}

Keywords: Memory Encoding; Aging; Cognitive Rehabilitation; Mild Cognitive Impairment;

Event-Related Potentials

\section{INTRODUCTION}

The advance of technology has allowed individuals to live longer, creating an aging population [1]. Psychological changes such as a decline in memory accompany the physiological aging process. Indeed, it has been estimated that $40 \%$ of people aged 60 years or older in the United States experience memory decline [2,3].

From an information-processing point of view, memory formation and retrieval involves three stages: encod-

${ }^{*}$ The authors report no conflicts of interest.

\#Corresponding author. ing, storage, and retrieval [4]. In cases of memory decline, common intervention strategies suggested in rehabilitation include lowering the demand for memory recall (which minimizes the retrieval stage). Such strategies mostly focus on helping people to compensate for their memory difficulties, and include the use of memory aids such as reminder notes, a daily planner, creating a routine of daily activities, and making changes to the environment $[5,6]$. However, if information encoding has been deficient in the first place-which can be a problem in people with mild cognitive impairments (MCI) [7] - remediating at the retrieval stage may not help to solve the basic problem. Instead, working to improve encoding should further improve memory performance. However, modulating the processes an individual requires to absorb information and to improve encoding is not commonly practiced. This could be because of ambiguity in the factors involved in the encoding process, which could lead to uncertainty about what exactly enables successful encoding. A better understanding of what correlates with successful encoding, encoding deficiencies, and potential strategies to improve encoding should therefore be beneficial clinically.

Cognitive neuroscientists have used a number of techniques to study memory encoding, including event-related potentials (ERPs) and functional magnetic resonance imaging (fMRI). ERP techniques, with temporal resolution on a millisecond (ms) scale, allow for the precise measurement of electrical activities (in microvolts) that are a direct result of cognitive processes. This review will discuss ERP studies of memory encoding which have explored the initial cognitive processes and particularly those which employed the subsequent memory research paradigm. This paradigm involves participants completing study trials in which they encode information; afterwards completing test trials in which they attempt to retrieve the information encoded. Correct recall during the test trials reflects successful encoding. ERPs are recorded, in particular during the study trials. Those 
ERPs can subsequently be categorized according to whether or not the participant could identify the study items correctly at the subsequent recognition phase (i.e., during the test trials). The ERPs of study items identified correctly in the test trials usually display more positive potentials than the ERPs of study trials incorrectly identified. Using this technique, brain activity during successful (i.e. correct trials) and unsuccessful (incorrect trials) encoding can be differentiated. The differential activity between successful and unsuccessful encoding is termed the subsequent memory effect (SME). The SME generally emerges after $400 \mathrm{~ms}$ post stimulus [8].

In this paper, factors associated with the successful encoding (as reflected by the SME) were reviewed. The relevance to the MCI population was also discussed.

\section{MATERIALS AND METHODS}

Reports of research published from January 1980 to December 2010 which appeared in the databases of CINAHL (1982-to date), MEDLINE (1966-to date), AMED (1985to date), Journals@Ovid and the ISI Web of Science (1900-to date for both) were collected and reviewed. The reference lists of the review articles by Friedman and Johnson [9] and Friedman, et al. [10] were also reviewed. The main criteria for inclusion were studies which dealt with memory encoding and 1) used the ERP technique; 2) used the subsequent memory paradigm; and 3) studied normal adult and MCI participants. The key terms used in searching for articles were "ERP," "subsequent memory," and "encoding" (with related terms also checked). Only reports published in English were considered. A total of 145 articles were found using these criteria. If the title indicated that it was an ERP study, the abstract was read to assess whether or not the paper should be included. Altogether, 17 studies were given full review, as summarized in Table $\mathbf{1}$.

\subsection{Factors Associated with the SME}

The factors found in these 17 studies to influence the emergence of the SME were the nature of the materials or stimuli, the modes of encoding and the nature of the retrieval task. Overall, SME appeared to emerge more consistently when the material being encoded was considered relevant by the subject. Semantic processing is associated with larger SME amplitude and was often associated with better recognition performance. And retrieval performance suggested that the amount of memory traces formed at encoding was related to the strength of the SME. The following three sections summarize the findings for young healthy participants (age 18 - 38).

\subsubsection{Materials}

Twelve of the 17 studies used verbal material (i.e., words) as the material for encoding and later retrieval testing.
This included the use of single words in English [8, 11-17], in Spanish [18], and in German [19]. Nouns in a sentence context [20] and paired words [21] were also used. These studies commonly found that the ERPs associated with the SME were widespread across the brain $[14,16,18-20]$. Five studies used nonverbal pictorial materials such as pictures of objects [22-24], faces [25], or complex pictures of scenery [26], and these also elicited SMEs. Interestingly, the studies led by Duarte and Sommer found evidence that the ERPs associated with the SME were larger over the right brain hemisphere. This difference might be related to cerebral specialization (i.e., the use of the left hemisphere for verbal material and the right hemisphere for nonverbal material). Further research is needed to determine whether or not this lateralization is material-dependent, which would have implications for the choice of material to present to a person with a brain lesion. Van Petten and Senkfor [17] did not find the effect when using meaningless visual patterns. This suggests that for the emergence of the SME, the materials used may need to be already in an individual's knowledge base for associations to be formed. Future experiments using, for example, pseudo-words may provide clearer evidence about this. Overall, the results from the studies reviewed showed that both verbal and nonverbal familiar materials were associated with the SME.

\subsubsection{Encoding Modes and Tasks}

Encoding can be intentional or incidental. In the case of intentional encoding, participants are told in advance that they will be tested later for memory retrieval; on the other hand, incidental encoding happens when the participants do not know they will be tested. In both modes, participants can be asked to perform a task or tasks while they encode the information in the study trials. These tasks usually require semantic or perceptual processing of materials or stimuli. An example of a semantic task is to have the participant determine whether an item referred to by a word or picture is living or inanimate [24]. A perceptual task would be to ask participants to determine whether the first and last letters of a word are in alphabetical order [13].

Of the 17 studies reviewed, six engaged their participants in intentional encoding (with or without a perceptual or semantic task), and each of the six found signifycant SME $[8,11,19,20,23,24]$. In the 11 studies which utilized incidental encoding, the SME was also consistently found.

Of the 11 incidental encoding studies, six included both semantic and perceptual tasks [12-15,17,21], three included only a semantic task [16,18,22], and two included only a perceptual task $[25,26]$. Semantic tasks were consistently associated with significant SMEs with predominately frontocentral distribution [13,17,21,22,24]. This 
Table 1. ERP studies and the subsequent memory paradigm.

\begin{tabular}{|c|c|c|c|c|c|c|}
\hline Study authors & $\begin{array}{c}\text { Year } \\
\text { published }\end{array}$ & $\begin{array}{l}\text { Sample size and } \\
\text { type }\end{array}$ & $\begin{array}{c}\text { Paradigm } \\
\text { (encoding, retrieval) }\end{array}$ & Task at encoding & Stimuli & SME \\
\hline $\begin{array}{l}\text { Bridger and } \\
\text { Wilding }\end{array}$ & 2010 & $\begin{array}{l}28 \text { (age } 19 \text { - 25, mean } \\
\quad=21 \text { ), } 3 \text { Male }(\mathrm{M})\end{array}$ & $\begin{array}{l}\text { Intentional, old/new } \\
\text { with confidence and } \\
\text { location judgments }\end{array}$ & $\begin{array}{l}1 \text { semantic, } 1 \\
\text { perceptual }\end{array}$ & English words & $\begin{array}{c}\text { Semantic_-frontal, Perceptual } \\
\text { —negative effect in } \\
\text { centroparietal }\end{array}$ \\
\hline $\begin{array}{l}\text { Cansino and } \\
\text { Trejo-Morales }\end{array}$ & 2008 & $\begin{array}{c}17(\text { mean }=22.5), 6 \\
M\end{array}$ & $\begin{array}{c}\text { Incidental, old/new } \\
\text { with source judgment }\end{array}$ & 1 semantic & Pictures of objects & $\begin{array}{l}\text { Bilateral frontal and right } \\
\text { central sites }\end{array}$ \\
\hline Cansino et al. & 2010 & $\begin{array}{l}14 \text { young (age } 21 \text { - } \\
\text { 27, mean = 22.9), } 6 \\
\text { M; } 14 \text { old (age } 71-77 \text {, } \\
\text { mean = 72.4), } 6 \mathrm{M}\end{array}$ & $\begin{array}{c}\text { Intentional but refrain } \\
\text { from self strategy, } \\
\text { old/new with source } \\
\text { judgment }\end{array}$ & 1 semantic & Pictures of objects & $\begin{array}{l}\text { Main in the frontal and central } \\
\text { sites, larger in old in parietal. }\end{array}$ \\
\hline Duarte et al. & 2004 & $\begin{array}{l}13 \text { (age } 18-25 \text {, mean } \\
\quad=19), 4 \mathrm{M}\end{array}$ & $\begin{array}{l}\text { Intentional, old/new } \\
\text { with remember/know } \\
\text { and source judgment }\end{array}$ & 2 semantic & Pictures of objects & $\begin{array}{l}\text { Largest in frontal and } \\
\text { prefrontal, right lateralized }\end{array}$ \\
\hline Friedman and Trott & 2000 & $\begin{array}{c}16 \text { (age } 21-28, \text { mean } \\
=25) ; 16 \text { (age } 65-81 \\
\text { mean }=71) \text {, no } \mathrm{M}\end{array}$ & $\begin{array}{c}\text { Intentional, old/new } \\
\text { with remember/know } \\
\text { and source judgment }\end{array}$ & $\mathrm{n} / \mathrm{a}$ & English words & Widespread \\
\hline Friedman et al. & 1996 & $\begin{array}{l}40 \text { young (mean } \\
\text { 26.4), } 7 \mathrm{M} \text {; } 40 \text { old } \\
\text { (mean = 69.8) } 7 \mathrm{M}\end{array}$ & $\begin{array}{l}\text { Incidental, stem com- } \\
\text { pletion and cue recall }\end{array}$ & $\begin{array}{l}1 \text { semantic, } 1 \\
\text { perceptual }\end{array}$ & English words & $\begin{array}{l}\text { SME effects reliable for young } \\
\text { subjects in semantic task, } \\
\text { centroparietal maximum }\end{array}$ \\
\hline Gutchess et al. & 2007 & $\begin{array}{l}20 \text { young (age } 18 \text { - } \\
26), 11 \mathrm{M} ; 20 \text { old } \\
(61-74) 10 \mathrm{M}\end{array}$ & $\begin{array}{l}\text { Incidental, old/new } \\
\text { with confidence judg- } \\
\text { ment }\end{array}$ & 1 perceptual & Pictures of scenes & $\begin{array}{l}\text { Frontocentral SME for both, } \\
\text { but for older subjects it did not } \\
\text { differ as a function of } \\
\text { confidence }\end{array}$ \\
\hline Mangels et al. & 2001 & $\begin{array}{l}20 \text { (age } 22 \text { - 37), } 11 \\
\text { M, } 5 \text { people dis- } \\
\text { carded in analysis }\end{array}$ & $\begin{array}{l}\text { Intentional, old new } \\
\text { with remember/know } \\
\text { and free recall }\end{array}$ & $\mathrm{n} / \mathrm{a}$ & English words & $\begin{array}{l}\text { Positive effect in frontal sites, } \\
\text { negative effect in posterior sites }\end{array}$ \\
\hline Paller et al. & 1987 & $\begin{array}{l}16 \text { (age } 18-28 \\
\text { mean = 21), } 8 \mathrm{M}\end{array}$ & $\begin{array}{l}\text { Incidental, old/new } \\
\text { with recall }\end{array}$ & $\begin{array}{l}2 \text { semantic and } 2 \\
\text { perceptual }\end{array}$ & English words & $\begin{array}{l}\text { Frontal, central, and posterior } \\
\text { sites, larger for semantic tasks }\end{array}$ \\
\hline Sanquist et al. & 1980 & $9,3 \mathrm{M}$ & $\begin{array}{l}\text { Incidental, old/new } \\
\text { recognition }\end{array}$ & $\begin{array}{l}1 \text { semantic, } 1 \text { pho- } \\
\text { nemic, and } 1 \text { per- } \\
\text { ceptual }\end{array}$ & English words & $\begin{array}{l}\text { Largest centroposterior, only } \\
\text { limited electrodes used }\end{array}$ \\
\hline Smith & 1993 & $27,14 \mathrm{M}$ & $\begin{array}{l}\text { Incidental, old } / \text { new } \\
\text { with remember/know } \\
\text { judgment }\end{array}$ & 1 semantic & English words & $\begin{array}{l}\text { Widespread, no difference } \\
\text { between remember and know }\end{array}$ \\
\hline Sommer et al. & 1991 & 10 (age 19 - 30), $7 \mathrm{M}$ & Incidental, old/new & 1 perceptual & Pictures of faces & $\begin{array}{l}\text { Positive effect in frontal, } \\
\text { negative effect in posterior sites } \\
\text { (larger over right hemisphere) }\end{array}$ \\
\hline $\begin{array}{l}\text { Tellez-Alanis } \\
\text { and Cansino }\end{array}$ & 2004 & $\begin{array}{c}12 \text { young } \\
\text { (mean = 23.7), } 6 \mathrm{M} \text {; } \\
12 \text { old (mean = 67), } \\
5 \mathrm{M}\end{array}$ & $\begin{array}{l}\text { Incidental and } \\
\text { intentional, old/new }\end{array}$ & 1 semantic & Spanish words & $\begin{array}{l}\text { Widespread, larger in incidental } \\
\text { in both young and old }\end{array}$ \\
\hline $\begin{array}{l}\text { Van Petten and } \\
\text { Senkfor }\end{array}$ & 1996 & $\begin{array}{l}16 \text { (age } 21 \text { - 38, } \\
\text { mean 23.8), no } \mathrm{M}\end{array}$ & Incidental, old/new & $\begin{array}{l}2 \text { semantic for } \\
\text { words, } 1 \text { perceptual } \\
\text { for visual patterns }\end{array}$ & $\begin{array}{l}\text { English words and } \\
\text { meaningless visual } \\
\text { patterns }\end{array}$ & $\begin{array}{l}\text { Larger in frontocentral region } \\
\text { for words, no SME for visual } \\
\text { patterns. }\end{array}$ \\
\hline Weyerts et al. & 1997 & $\begin{array}{c}18(21-32 \\
\text { mean }=24), 5 \mathrm{M}\end{array}$ & Incidental, old/new & $\begin{array}{l}1 \text { semantic and } 1 \\
\text { perceptual }\end{array}$ & German words & $\begin{array}{c}\text { In semantic task, largest at right } \\
\text { frontal }\end{array}$ \\
\hline
\end{tabular}

distribution might indicate frontal lobe involvement and that semantic processing involves this region. Excluding the one study that used a perceptual task with meaningless stimuli [17], five of the seven other studies that used a perceptual task showed SMEs. The ERP distributions observed in these studies were more varied, ranging from frontocentral, to centroparietal, to widespread. This variety makes it difficult to identify regions that might be important for perceptual processing. Worthy of note is that in one study [13], a negative effect (using a task that 
asked to determine if the first and last letter of a word is in alphabetical order) was identified rather than the positive difference usually found. On this basis, Otten and Rugg argued that perceptual processing is qualitatively different from semantic processing, though this result was not consistent with the findings of the other four studies that also used a perceptual task. This inconsistency may indicate that some "perceptual tasks" may require semantic or other elaborate processing in addition to perceptual processing, which could explain why topographic shapes are more varied in the studies that included a perceptual task.

Comparing semantic tasks with perceptual tasks, semantic tasks generally yielded a larger SME amplitude and superior recall $[14,21]$. This is consistent with the proposition that semantic processing leads to a greater likelihood that an item will be encoded into long-term memory [27]. Such findings also provide evidence that the magnitude of the SME may be associated with better memory performance [10].

Direct comparison between the two different modes of encoding was investigated by Tellez-Alanis and Cansino [18]. In their study, participants performed a semantic task in the incidental and intentional conditions, and the results showed that recognition rates were not differed between conditions and SME was present and of similar magnitude in both conditions (implying a similar amount of encoding). Firstly, this may indicate that the benefits of semantic information processing outweighed the benefits of the intention to remember since incidental tasks are associated with poorer recognition than intentional tasks when semantic processing is not explicitly required [28]. Secondly, this is consistent with the findings that magnitude of SME is associated with memory performance.

Overall, the important message from this section is that semantic processing of information is one of the best predictors on whether an item will be remembered.

\subsubsection{Retrieval Tasks}

A recognition test is commonly used to test retrieval. Participants are asked to make a decision about whether or not they have seen an item in the encoding or study period. Additional judgments participants might be asked to perform at retrieval include deciding whether they "remember" the viewing (defined as recalling contextual information such as mental images evoked during the study trials), whether they "know" they viewed the item (i.e., without contextual recall, whether they can identify when or where the item was studied), or the degree to which they are "confident" that they viewed it (their subjective belief in the accuracy of their judgment). Less common tasks include free recall (where participants recall the items seen without any cuing), stem comple- tion (recalling the items seen based on the first few letters of the items provided as cues), and partially cued recall (recalling the items seen with a cue provided). Each type of retrieval task makes different demands on cognition, with recognition being the easiest, free recall being the hardest, and stem completion and cued recall being somewhere in between [6].

Mangels, et al. [8] categorized encoding-related ERPs into free-recalled, remember, and know responses. The "free-recalled" ERPs had significantly greater average amplitude and greater SME amplitude than the "remember" and "know" responses in the frontal regions of young and healthy adults. In addition, the "remember" and "know" ERPs could be differentiated from each other in the late latency window (1500 to $2000 \mathrm{~ms}$ ). Two other studies that used either verbal or pictorial stimuli also found reliable differences between the average ERPs of "remember" and "know" responses [20,24]. In both of these cases, more positive SME amplitude was shown in the "remember" compared with the "know" responses of young participants. These differences were also exhibited when averaging according to "confidence," with "highly confident” judgments having more positive SME amplitude than "less confident" judgments [26]. However, there was one negative report where "remember" and "know" ERPs could not be differentiated from each other [16]. But because Smith [16] only analyzed his data till 900 ms post stimulus onset, it might have been possible that this differentiation happened later similar to the study by Mangels, et al. [8].

Regardless of the type of judgment involved, the underlying thought is that demand on retrieval is higher for "remember" or "more confident" judgments than for "know" or "less confident" judgments. Since accurate retrieval in demanding retrieval conditions depends on better encoding during study, it may be reasonable to assume that more memory traces (or associations) should have been formed at that time. The three studies mentioned above [20,24,26] showed more positivity and larger ERP amplitudes for more demanding tasks. In addition, one found that "free-recalled" ERPs were more positive than in either the "remember" or the "know" situation, and the "remember" and "know" ERPs could be differentiated from each other in late window [8]. Smith [16] found no judgement dependence at all, but might be because analyses were not conducted in late windows. Overall, evidence from the retrieval task results indicate that SME may track the amount of associations formed at encoding, with a stronger (larger) SME for more associations formed. In addition, it appears that encoding with contextual details (indicated by the SME for "remember" judgments) is also associated with larger SME amplitude and might be differentiable from encoding without such details (indicated by the SME for "know" 
judgments).

In summary, the SME is an index of encoding $[29,30]$. This effect appears to emerge more consistently when the encoded materials are relevant to a person; it is also larger when information is processed semantically and when context-relevant information is added at encoding.

The topographical patterns indicate that the SME can be distributed across the frontal, central, and parietal regions, with some evidence of lateralization associated with non-verbal or pictorial stimuli [22,25]. Given that the SME's latency and scalp distribution can be similar to the well-studied P3 component of ERPs which have been related to attention and working memory, the SME may, at least in part, reflect similar operations. This is more likely to be the case for the central and parietal regions [31]. A frontal SME is apparently elicited when more strategic encoding operations are required [13,17, 21,22,24]. Effects in this region may reflect encoding processes that allow for elaboration of information in working memory or transferring information back to the long-term memory [8].

\subsection{Encoding Differences between Young and Old}

Five of the reports evaluated described studies that included both young and old participants [12,18,20,23,26]. Types of stimuli and encoding modes were manipulated, and this allowed for some examination of differences in ability to encode between these two groups of participants.

Across the five studies, single words, words in a sentence, and complex pictures of scenery were used as the materials for encoding. A 1996 study led by Friedman and Gutchess used an incidental paradigm, Friedman and Trott [20] and Cansino, et al. [23] used an intentional paradigm, and Tellez-Alanis and Cansino [18] directly compared the two modes.

In their 1996 study, Friedman and colleagues found a reliable SME in the younger participants with their semantic task, but not apparent in the older ones. This finding would seem to conflict with the later findings of the other four studies, which showed that SMEs emerged in both younger and older people's ERP data. Different methodologies may explain the discrepancy. In Friedman, et al. [12] the words were presented twice at encoding, and subsequent ERP analyses were conducted collapsing the two stimulus presentations. Thus repetition effects - which were evident in their young participants' data but not in that of their older participants' data-might have influenced the results.

Friedman and Trott [20] used an intentional paradigm without an encoding task (but with "remember" and "know" judgments in the retrieval test). Their results showed that an SME was elicited for in older group when ERPs "remember" and "know" judgments were averaged separately, but the average strength of the SME did not differ between the "remember" and "know" judgments. Similar results were found by the Gutchess, et al. [26] group where their older group's SME did not differ as a function of their "confidence" in the encoded information. These two studies indicated that either older people performed similarly in processing on all the information or the processing performed on the information resulted in the same amount of associations formed. Alternatively, Friedman and Trott [20] suggested that older participants might have adopted a more liberal mindset when choosing "remember" or "know" responses in the retrieval test.

When a semantic task was required in an intentional design, Cansino, et al. [23] observed significant SMEs (similar in overall magnitude) in both groups. However, the distribution of SME was different between the two groups. While in young participants SME was significant in the frontal and central sites, the effect was smaller and extended to and was significantly larger in the older group in the parietal sites. This shifting of SME distribution (i.e. towards a more centroparietal distribution, which is more common in studies that use a perceptual task) may indicate that older participants rely more on perceptual processing strategies performed by the posterior neocortical regions, in addition to operations indicated by frontal SME; this result was regarded as inefficient encoding mechanism in older adults because younger adults relied more on the operations indicated by frontal SMEs. TellezAlanis and Cansino [18] also found that both intentional, as well as incidental, encoding with semantic processing elicited SMEs of similar magnitude for both groups of participants. In addition, there was no indication that SME distribution differed between groups. This result should not be seem as contradictory to Cansino, et al. [23] because Tellez-Alanis and Cansino [18] only analyzed data till $850 \mathrm{~ms}$; in Cansino, et al. [23], the distribution difference was observed between 800 and 1200 ms.

It is worth noting that both studies by Friedman and Trott [20] and Gutchess, et al. [26] yielded significant SMEs in the elderly, and showed a consistent effect of prior exposure even though there was no difference between the SMEs of "remember" (contextual) and "know" judgments, or in judgments with different levels of confidence. Such findings suggest that older adults process all information similarly without much elaboration [32]. This leads to an overall decrease in memory strength on the to-be-remembered items [6]. Thus, the memory strength on each item may be similar or less likely to be significantly different, irrespective of whether the item is later "remembered" or "known". Further, and the ERPs elicited during encoding cannot differentiate between these two outcomes. The notion that older adults process information without elaboration receives some support from Cansino, et al. [23]. This is because in that study 
even with the explicit semantic task (which was not required in both remember-know studies), older sample still relied more heavily on the posterior regions, rather than on the frontal regions for strategic operations. As has been mentioned, these results from Friedman and Trott [20] and Gutchess, et al. [26] could also be explained by the possibility that the older adults adopted a more liberal criterion when they made judgments in the test. This possibility is supported by the selective increase in the false alarm rate in the elderly found by all four of the research groups that found positive SMEs in the elderly. Therefore, when averaging ERPs at encoding based on these judgments, any differences between them would have been obscured and no reliable differences found. A liberal mindset could be interpreted as a retrieval-specific deficit. However, it is also plausible that older adults might have simply forgotten the stimuli more rapidly than the younger participants in these experiments.

A number of theories have attempted to explain agerelated changes in memory. These include slower processing speed [33], inefficiency in erasing information no longer needed in working memory [34], a decrease in memory processing which requires conscious control [35], and reduced resources for processing such as a decreased attention resources needed for effortful cognitive processing [36]. ERP studies may not be particularly suited to testing such theories, but they may be able to contribute to them. For example, it has been explained how evidence from ERP studies using the subsequent memory paradigm with older participants showed that they may encode without elaboration [9,26,32]. Considering the cognitive processes deemed to underlie SMEs and changes in SME distribution, less elaborated encoding in elderly participants could suggest altered working memory functions as well as reduced processing resources.

\subsection{Relevance to Mild Cognitive Impairment}

MCI is defined as a cognitive decline that slightly exceeds that expected for a person's age and education level [37]. When the cognitive decline is related to memory the person may be considered to have amnesic MCI. MCI is considered to be a transitional stage from normal decline to dementia [7]. This is an important, though relatively young, research area because more than half of MCI sufferers progress to dementia within five years [37].

No studies were found that had investigated the SMEs in relation to $\mathrm{MCI}$. Other research that investigated MCI's encoding abilities and MCI's ERP waveforms were found and discussed.

\subsubsection{Encoding Deficits in MCI}

Behavioural studies [38-45] have reported impaired free recall, cued recall, and recognition of faces and verbal material among people with MCI. These difficulties should arise from deficits in encoding and retrieval processes, though the encoding processes have been suggested to be primarily responsible [46,47]. One aspect of their encoding deficits seems to be the failure to utilize semantic knowledge to enhance encoding [44]. In a study conducted by Belleville and colleagues [48], the recognition performance of normal older adults and that of persons with MCI were compared in two conditions. In the first condition, no instruction was given as to how best to memorize the items during encoding; in the second condition, the participants were oriented to the semantic properties of the items. Interestingly, both groups exhibited similar performance when not given specific instructions on how to memorize. However, the performance of persons with MCI was much worse in the orientation condition when compared to the performance of the other group, highlighting problems with processing the semantic properties of the items. Similar to this result, but conducted with persons with reversible memory disorder (RMD) and MCI, persons with RMD showed better performance than persons with MCI when using a semantic strategy during encoding [49]. Such findings indicate that people with MCI have marked encoding deficits. These deficits, however, do not seem to be due to a deficient access to the still-preserved semantic system [50] since persons with MCI are still sensitive to the semantic content of the materials [7]. Rather, these deficits may be due to an inability to bind contextual elements within an episode, or a lack of efficiency in doing so [50]. If this is the case, the episodic memory performance of persons with MCI should also be affected. Indeed, behavioural results indicate that people with MCI often display episodic memory impairment [45,51,52]. In a six-year cohort study, Bennett, et al. [51] reported that participants with MCI showed more rapid declines in episodic memory than was the case for older controls based on several clinical tests. Further evidence comes from recent studies that compared structures subserving episodic encoding in MCI and healthy controls. These studies found structural changes including the hippocampus, which is an important area for binding contextual elements with an episode [53,54]. These structural changes can be assumed to contribute to episodic deficits in MCI.

While, to the best of our knowledge, no ERP studies have used a paradigm that examined SMEs, some ERP studies have confirmed theories about or provided insight into how the brain of MCI sufferers functions. In the ERP studies, a prolonged response time correlated with P300 latency (a positive wave that peaks at about 300 to 500ms poststimulus onset and that indexes attention and probably memory operations) was found, compared to 
normal controls [e.g. 55-57]. This suggests further cognitive slowing in MCI sufferers as compared to individuals experiencing normal aging that may primarily originate from P300 slowing. In another investigation using a longitudinal design, a group Olichney, et al. [58] examined MCI with a word repetition protocol looking for ERP components that could differentiate those persons more likely to progress to dementia. Their participants were asked to determine whether a target word would fit into a semantic category presented earlier in the trial. The P600 component (a positive wave at about 600 ms poststimulus onset that indexes the updating of the content in working memory and the encoding of episodic information into memory for long-term use) and the N400 component (a negative wave at about $400 \mathrm{~ms}$ poststimulus onset that represents loading for semantic processing and semantic expectancy) have both been implicated using this procedure $[14,59,60]$. Olichney's 2008 study subsequently showed that abnormalities in the P600 and N400 waves are associated with an increased risk of MCI converting to dementia. Even though the primary goal of the study was to predict who within the MCI group would be at risk of conversion, the results also suggested potential abnormalities in these components associated with semantic processing and episodic memory. In another work, a group led by Tales, et al. [61] investigated mismatch negativity between 140 and 250 ms poststimulus reflecting pre-attentive processes to detect changes in the visual field. They reported that abnormalities during this interval might signal higher level processing deficits, such as in episodic memory, in cases of MCI. Overall, a number of ERP components representing pre-attentive processing, semantic processing and episodic encoding processes might be affected in MCI situations. The ERP findings are consistent with the behavioural and structural change findings reviewed earlier.

\subsubsection{SMEs and Encoding with MCI}

The results from the SME studies detailed thus far show that memory is stronger when more associations have been formed at encoding. These studies also indicate that semantic processing and context-relevant information may be associated with stronger encoding. Although participants with MCI (unlike healthy elderly) do not appear to benefit fully from semantic cuing [40,44], it is possible that a single semantic cue is insufficient to trigger their semantic processing of information. With additional and extended memory strategy training focusing on an elaborative type of encoding, memory performance might be improved for people with MCI. Indeed, a number of studies have reported the beneficial effects of cognitive training [40,62-64]. In a study conducted by Belleville, et al. [65], the participants were taught strategies such as interactive imagery, face-name association, verbal or- ganization, categorization, ordering, and the method of loci in an attempt to improve their episodic memory. It should be noted that in Belleville et al.'s study, both verbal (face-name association, verbal organization, categorization, ordering) and nonverbal methods (interactive imagery, the method of loci) were employed. These strategies assisted in linking the information, whichusing the terminology in the SME literature-would be associated with semantic processing. The results showed that older persons with MCI and normal elderly both improved in terms of outcome measures, including delayed list recall and face-name association. Importantly, the MCI sufferers made improvements on a par with those of the normal elderly. These results may be pointing to the potential benefits of associative and extended memory strategy training for people with MCI. If so, rehabilitation programs for people with MCI should focus on improving semantic processing and episodic memory through elaborative encoding training. Indeed, this proposal has received recent support from the findings of a neuroimaging study [66]. In this study, after cognitive training MCI sufferers were able to recruit alternative areas in addition to areas activated prior to treatment. Furthermore, the differences in patterns of activation during encoding and retrieval were attenuated between the MCI and control groups after the training. This positive result indicates that the brain of MCI sufferers remains sufficiently plastic to allow neural changes with proper intervention.

\subsubsection{SME in MCI}

Future ERP research with MCI subjects might profitably examine their SMEs in response to different stimuli and task conditions. The SME could be used as an index to examine if they would respond better to verbal or nonverbal stimuli. It could also be used to compare the patterns of effect between MCI sufferers and the healthy elderly under the same task conditions. Semantic tasks that investigate semantic processing abilities could be investigated first, since the SME patterns are fairly consistent in the healthy young and older people. Why people with MCI do not benefit as much as the normal elderly from supportive cues [40] might be a promising topic for future research. Earlier ERP indications associated with an abnormal SME might also be worthy of further research. Finally, experiments might also be set up with MCI subjects to explore differences in SME patterns before and after cognitive training.

\section{CONCLUSIONS}

ERP studies using different types of material, encoding modes, and retrieval tasks have offered insights into the factors associated with memory encoding. ERP findings 
indicate that semantic processing of information is associated with a larger SME and better memory performance. This may be because semantic processing enriches memory traces and thus the chance that the information will be remembered.

The results from older adults suggest that they encode with more perceptual emphasis and without elaboration. Therefore, their ERPs cannot be differentiated when sorted according to judgements assumed to have different memory strength requirement during encoding. The results could also indicate a retrieval-specific deficit.

Looking at the ERP findings from normal younger and older adults and the findings from participants with MCI, two characteristics differentiate normal aging and MCI: more impaired semantic processing and poorer episodic memory [7]. However, episodic memory can be improved through training in the elaborative encoding of information, which prompts positive neural changes in people with MCI $[40,66]$.

\section{ACKNOWLEDGEMENTS}

The work was supported by a grant from the Research Grants Council of the Hong Kong Special Administrative Region, China (Project No. PolyU 5620/07M) awarded to K. P. Y. Liu.

\section{REFERENCES}

[1] Romàn, G.C. (2002) Vascular dementia revisited: Diagnosis, pathogenesis, treatment, and prevention. Medical Clinics of North America, 86, 477-499. doi:10.1016/S0025-7125(02)00008-1

[2] Hanninen, T., Koivisto, K., Reinikainen, K.J., Helkala, E., Soininen, H., Mykkanen, L., Laakso, M. and Riekkinen, P.J. (1996) Prevalence of ageing-associated cognitive decline in an elderly population. Age and Ageing, 25, 201205. doi:10.1093/ageing/25.3.201

[3] Small, S.A. (2001) Age-related memory decline. Archives of Neurology, 58, 360-364. doi:10.1001/archneur.58.3.360

[4] Anderson, J.R. (2000) Learning and memory. Wiley, New York.

[5] Clare, L., Wilson, B.A., Carter, G., Gosses, A., Breen, K. and Hodges, J.R. (2000) Intervening with everyday memory problems in early Alzheimer's disease: An errorless learning approach. Journal of Clinical and Experimental Neuropsychology, 22, 132-146. doi:10.1076/1380-3395(200002)22:1;1-8;FT132

[6] Luo, L. and Craik, F.I.M. (2008) Aging and memory: A cognitive approach. Canadian Journal of Psychiatry, 53, 346-353.

[7] Belleville, S., Sylvain-Roy, S., de Boysson, C. and Menard, M.-C. (2008) Characterizing the memory changes in persons with mild cognitive impairment. In: Sossin, W.S., Lacaille, J.-C., Castellucci, V.F. and Belleville, S., Eds., Progress in Brain Research Essence of Memory,
Elsevier Science Publishers, Amsterdam, 365-375. doi:10.1016/S0079-6123(07)00023-4

[8] Mangels, J.A., Picton, T.W. and Craik, F.I.M. (2001) Attention and successful episodic encoding: An eventrelated potential study. Cognitive Brain Research, 11, 7795. doi:10.1016/S0926-6410(00)00066-5

[9] Friedman, D. and Johnson, R. Jr. (2000) Event-related potential (ERP) studies of memory encoding and retrieval: A selective review. Microscopy Research and Technique, 51, 6-28.

doi:10.1002/1097-0029(20001001)51:1<6::AID-JEMT2> 3.0.CO;2-R

[10] Friedman, D., Nessler, D. and Johnson, R. (2007) Memory encoding and retrieval in the aging brain. Clinical EEG \& Neuroscience, 38, 2-7. doi:10.1177/155005940703800105

[11] Bridger, E.K and Wilding, E.L. (2010) Requirements at retrieval modulate subsequent memory effects: An eventrelated potential study. Cognitive Neuroscience, 1, 254260.

[12] Friedman, D., Ritter, W. and Snodgrass, J.G. (1996) ERPs during study as a function of subsequent direct and indirect memory testing in young and old adults. Cognitive Brain Research, 4, 1-13.

[13] Otten, L.J. and Rugg, M.D. (2001) Electrophysiological correlates of memory encoding are task-dependent. Cognitive Brain Research, 12, 11-18.

[14] Paller, K., Kutas, M. and Mayes, A.R. (1987) Neural correlates of encoding in an incidental learning paradigm. Electroencephalography and Clinical Neurophysiology, 67, 360-371. doi:10.1016/0013-4694(87)90124-6

[15] Sanquist, T.F., Rohrbaugh, J.W., Syndulko, K. and Lindsley, D. (1980) Electrocortical signs of levels of processing: perceptual analysis and recognition memory. Psychophysiology, 17, 568-576. doi:10.1111/j.1469-8986.1980.tb02299.x

[16] Smith, M. E. (1993) Neurophysiological manifestations of recollective experience during recognition memory judgments. Journal of Cognitive Neuroscience, 5, 1-13. doi:10.1162/jocn.1993.5.1.1

[17] Van Petten, C. and Senkfor, A.J. (1996) Memory for words and novel visual patterns: Repetition, recognition, and encoding effects in the event-related brain potentials. Psychophysiology, 33, 491-506. doi:10.1111/j.1469-8986.1996.tb02425.x

[18] Tellez-Alanis, B. and Cansino, S. (2004) Incidental and intentional encoding in young and elderly adults. Neuroreport, 15, 1819-1823. doi:10.1097/01.wnr.0000137075.41257.98

[19] Fernandez, G., Weyerts, H., Tendolkar, I., Smid, H.G., Scholz, M. and Heinze, H.J. (1998) Event-related potentials of verbal encoding into episodic memory: Dissociation between the effects of subsequent memory performance and distinctiveness. Psychophysiology, 35, 709-720. doi:10.1111/1469-8986.3560709

[20] Friedman, D. and Trott, C. (2000) An event-related potential study of encoding in young and older adults. $\mathrm{Neu}$ ropsychologia, 38, 542-557. 


\section{doi:10.1016/S0028-3932(99)00122-0}

[21] Weyerts, H., Tendolkar, I., Smid, H.G. and Heinze, H.J. (1997) ERPs to encoding and recognition in two different inter-item association tasks. Neuroreport, 8, 1583-1588. doi:10.1097/00001756-199705060-00007

[22] Cansino, S. and Trejo-Morales, P. (2008) Neurophysiology of successful encoding and retrieval of source memory. Cognitive, Affective and Behavioral Neuroscience, 8, 85-98. doi:10.3758/CABN.8.1.85

[23] Cansino, S., Trejo-Morales, P. and Hernández-Ramos, E. (2010) Age-related changes in neural activity during source memory encoding in young, middle-aged and elderly adults. Neuropsychologia, 48, 2537-2549. doi:10.1016/j.neuropsychologia.2010.04.032

[24] Duarte, A., Ranganath, C., Winward, L., Hayward, D. and Knight, R. (2004) Dissociable neural correlates for familiarity and recollection during the encoding and retrieval of pictures. Cognitive Brain Research, 18, 255272. doi:10.1016/j.cogbrainres.2003.10.010

[25] Sommer, W., Schweinberger, S.R. and Matt, J. (1991) Human brain potential correlates of face encoding into memory. Electroencephalography and Clinical Neurophysiology, 79, 457-463. doi:10.1016/0013-4694(91)90165-Z

[26] Gutchess, A.H., Ieuji, Y. and Federmeier, K.D. (2007) Event-related potentials reveal age differences in the encoding and recognition of scenes. Journal of Cognitive Neuroscience, 19, 1089-1103. doi:10.1162/jocn.2007.19.7.1089

[27] Craik, F.I.M. (1983) On the transfer of information from temporary to permanent memory. Philosophical Transactions of the Royal Society of London. Series B, Biological Sciences, B301, 341-359. doi:10.1098/rstb.1983.0059

[28] Noldy, N.E., Stelmack, R.M. and Campbell, K.B. (1990) Event-related potentials and recognition memory for pictures and words: The effects of intentional and incidental learning. Psychophysiology, 27, 417-428. doi:10.1111/j.1469-8986.1990.tb02337.x

[29] Johnson, R. (1995) Event-related potential insights into the neurobiology of memory systems. In: Boller, F. and Grafman, J., Eds., The Handbook of Neuropsychology, Elsevier Science Publishers, Amsterdam, 135-164.

[30] Wagner, A.D., Koutstaal, W. and Schacter, D.L. (1999) When encoding yields remembering: Insights from eventrelated neuroimaging. Philosophical Transactions of the Royal Society of London. Series B, Biological Sciences, 354, 1307-1324. doi:10.1098/rstb.1999.0481

[31] Grune, K., Metzb, A., Hagendorfa, H. and Fischer, S. (1996) Information processing in working memory and event-related brain potentials. International Journal of Psychophysiology, 23, 111-120. doi:10.1016/0167-8760(96)00040-2

[32] Nessler, D., Johnson, R., Bersick, M. and Friedman, D. (2006) On why the elderly have normal semantic retrieval but deficient episodic encoding: A study of left inferior frontal ERP activity. Neuroimage, 30, 299-312. doi:10.1016/j.neuroimage.2005.09.005

[33] Salthouse, T. (1996) The processing-speed theory of adult age differences in cognition. Psychological Review, 103, 403-428. doi:10.1037/0033-295X.103.3.403

[34] Hasher, L. and Zacks, R.T. (1988) Working memory, comprehension, and aging: A review and a new view. In: Bower, G.H., Ed., The Psychology of Learning and Motivation: Advances in Research and Theory, Academic Press, San Diego, 193-225.

[35] Hasher, L. and Zacks, R.T. (1979) Automatic and effortful processes in memory. Journal of Experimental Psychology: General, 108, 356-388. doi:10.1037/0096-3445.108.3.356

[36] Craik, F.I.M. and Byrd, M. (1982) Aging and cognitive deficits: The role of attentional resources. In: Craik, F.I.M. and Trehub, S.E., Eds., Aging and Cognitive Processes, Plenum Press, New York, 191-211.

[37] Gauthier, S., Reisberg, B., Zaudig, M., Petersen, R., Ritchie, K., Broich, K., Belleville, S., Brodaty, H., Bennett, D. and Chertkow, H. (2006) Mild cognitive impairment. Lancet, 367, 1262-1270. doi:10.1016/S0140-6736(06)68542-5

[38] Bennett, I.J., Golob, E.J., Parker, E.S. and Starr, A. (2006) Memory evaluation in mild cognitive impairment using recall and recognition tests. Journal of Clinical and Experimental Neuropsychology, 28, 1408-1422. doi:10.1080/13803390500409583

[39] Dudas, R.B., Clague, F., Thompson, S.A., Graham, K.S. and Hodges, J.R. (2005) Episodic and semantic memory in mild cognitive impairment. Neuropsychologia, 43, 1266-1276. doi:10.1016/j.neuropsychologia.2004.12.005

[40] Hudon, C., Belleville, S., Souchay, C., Gely-Nargeot, M.-C., Chertkow, H. and Gauthier, S. (2006) Memory for gist and detail information in Alzheimer's disease and mild cognitive impairment. Neuropsychology, 20, 566577. doi:10.1037/0894-4105.20.5.566

[41] Ivanoiu, A., Adam, S., Van der Linden, M., Salmon, E., Juillerat, A.-C., Mulligan, R. and Seron, X. (2005) Memory evaluation with a new cued recall test in patient with mild cognitive impairment and Alzheimer's disease. Journal of Neurology, 252, 47-55. doi:10.1007/s00415-005-0597-2

[42] Loewenstein, D.A., Acevedo, A., Luis, C., Crum, T., Barker, W. and Duara, R. (2004) Semantic interference deficits and the detection of mild Alzheimer's disease and mild cognitive impairment without dementia. Journal of the International Neuropsychological Society, 10, 91-100. doi:10.1017/S1355617704101112

[43] Nordahl, C.W., Ranganath, C., Yonelinas, A.P., DeCarli, C., Reed, B.R. and Jagust, W.J. (2005) Different mechanisms of episodic memory failure in mild cognitive impairment. Neuropsychologia, 43, 1688-1697. doi:10.1016/j.neuropsychologia.2005.01.003

[44] Perri, R., Carlesimo, G.A., Serra, L., Caltagirone, C. and The Early Diagnosis Group of the Italian Interdisciplinary Network on Alzheimer's Disease. (2005) Characterization of memory profile in subjects with amnestic mild cognitive impairment. Journal of Clinical and Experimental Neuropsychology, 27, 1033-1055. doi:10.1080/13803390490919317 
[45] Petersen, R. C. (2003) Mild cognitive impairment: Aging to Alzheimer's disease. Oxford University Press, Oxford.

[46] Wang, Q.S. and Zhou, J.N. (2002) Retrieval and encoding of episodic memory in normal aging and patients with mild cognitive impairment. Brain Research, 924, 113-115. doi:10.1016/S0006-8993(01)03200-0

[47] Clément, F., Belleville, S. and Mellah, S. (2010) Functional neuroanatomy of the encoding and retrieval processes of verbal episodic memory in MCI. Cortex, 46, 1005-1015. doi:10.1016/j.cortex.2009.07.003

[48] Belleville, S., Chatelois, J., Fontaine, F. and Peretz, I. (2002) Mémoria: Batterie informatisée d’évaluation de la mémoire pour Mac et PC. Institut Universitaire de Gériatrie de Montréal, Montreal.

[49] Perri, R., Carlesimo, G.A, Serra, L., Caltagirone, C. and Early Diagnosis Group of the Italian Interdisciplinary Network on Alzheimer's Disease (2009) When the amnestic mild cognitive impairment disappears: Characterisation of the memory profile. Cognitive and Behavioral Neurology, 22, 109-116. doi:10.1097/WNN.0b013e3181a7225c

[50] Atienza, M., Atalaia-Silva, K.C., Gonzalez-Escamilla, G., Gil-Neciga, E., Suarez-Gonzalez, A. and Cantero, J.L. (2011) Associative memory deficits in mild cognitive impairment: The role of hippocampal formation. Neuroimage, 57, 1331-1142. doi:10.1016/j.neuroimage.2011.05.047

[51] Bennett, D.A., Wilson, R.S., Schneider, J.A., Evans, D.A., Beckett, L.A., Aggarwal, N.T., Barnes, L.L., Fox, J.H. and Bach, J. (2002) Natural history of mild cognitive impairment in older persons. Neurology, 59, 198-205.

[52] Perry, R.J. and Hodges, J.R. (1999) Attention and executive deficits in Alzheimer's disease: A critical review. Brain, 122, 383-404. doi:10.1093/brain/122.3.383

[53] Leube, D.T., Weis, S., Freymann, K., Erb, M., Jessen, F., Heun, R., Grodd, W. and Kircher, T. T. (2008) Neural correlates of verbal episodic memory in patients with MCI and Alzheimer's disease-A VBM study. International Journal of Geriatric Psychiatry, 23, 1114-1118. doi:10.1002/gps.2036

[54] Yassa, M.A., Stark, S.M., Bakker, A., Albert, M.S., Gallagher, M. and Stark, C.E. (2010) High-resolution structural and functional MRI of hippocampal CA3 and dentate gyrus in patients with amnestic Mild Cognitive Impairment. Neuroimage, 51, 1242-1252. doi:10.1016/j.neuroimage.2010.03.040

[55] Papaliagkas, V.T., Anogianakis, G., Tsolaki, M.N., Koliakos, G. and Kimiskidis, V.K. (2010) Combination of P300 and CSF $\beta$-amyloid(1-42) assays may provide a potential tool in the early diagnosis of Alzheimer's disease. Current Alzheimer Research, 7, 295-299. doi:10.2174/156720510791162421

[56] Chapman, R.M., McCrary, J.W., Gardner, M.N., Sandoval, T.C., Guillily, M.D., Reilly, L.A. and Degrush, E. (2011) Brain ERP components predict which individuals progress to Alzheimer's disease and which do not. Neurobiology of Aging, 32, 1742-1755. doi:10.1016/j.neurobiolaging.2009.11.010
[57] Van Deursen, J.A., Vuurman, E.F., Smits, L.L., Verhey, F.R. and Riedel, W.J. (2009) Response speed, contingent negative variation and P300 in Alzheimer's disease and MCI. Brain and Cognition, 69, 592-599. doi:10.1016/j.bandc.2008.12.007

[58] Olichney, J.M., Taylor, J.R., Gatherwright, J., Salmon, D.P., Bressler, A.J., Kutas, M. and Iragui-Madoz, V.J. (2008) Patients with MCI and N400 or P600 abnormalities are at very high risk for conversion to dementia. Neurology, 70, 1763-1770. doi:10.1212/01.wnl.0000281689.28759.ab

[59] Helmstaedter, C., Grunwald, T., Lehnertz, K., Gleibner, U. and Elger, C. (1997) Differential involvement of left temporolateral and temporomesial structures in verbal declarative learning and memory: Evidence from temporal lobe epilepsy. Brain and Cognition, 35, 110-131. doi:10.1006/brcg.1997.0930

[60] Paller, K. (1990) Recall and stem-completion priming have different electrophysiological correlates and are modified differentially by directed forgetting. Journal of Experimental Psychology: Learning, Memory, and Cognition, 1021-1032. doi:10.1037/0278-7393.16.6.1021

[61] Tales, A., Haworth, J., Wilcock, G., Newton, P. and Butler, S. (2008) Visual mismatch negativity highlights abnormal pre-attentive visual processing in mild cognitive impairment and Alzheimer's disease. Neuropsychologia, 46, 1224-1232. doi:10.1016/j.neuropsychologia.2007.11.017

[62] Olazaran, J., Muñiz, R., Reisberg, B., Peña-Casanova, J., del Ser, T., Cruz-Jentoft, A.J., Serrano, P., Navarro, E., García de la Rocha, M.L., Frank, A., Galiano, M. Fernández-Bullido, Y., Serra, J.A., González-Salvador, M.T. and Sevilla, C. (2004) Benefits of cognitive-motor intervention in MCI and mild to moderate Alzheimer disease. Neurology, 63, 2348-2353.

[63] Rozzini, L., Costardi, D., Vicini Chilovi, B., Franzoni, S., Trabucchi, M. and Padovani, A. (2007) Efficacy of cognitive rehabilitation in patients with mild cognitive impairment treated with cholinesterase inhibitors. International Journal of Geriatric Psychiatry, 22, 356-360. doi:10.1002/gps.1681

[64] Talassi, E., Guerreschi, M., Feriani, M., Fedi, V., Bianchetti, A. and Trabucchi, M. (2007) Effectiveness of a cognitive rehabilitation program in mild dementia (MD) and mild cognitive impairment (MCI): A case control study. Archives of Gerontology and Geriatrics, 44, 391399. doi:10.1016/j.archger.2007.01.055

[65] Belleville, S., Gilbert, B., Fontaine, F., Gagnon, L., Ménard, E. and Gauthier, S. (2006) Improvement of episodic memory in persons with mild cognitive impairment and healthy older adults: Evidence from a cognitive intervention program. Dementia and Geriatric Cognitive Disorders, 22, 486-499. doi:10.1159/000096316

[66] Belleville, S., Clément, F., Mellah, S., Gilbert, B., Fontaine, F. and Gauthier, S. (In press) Training-related brain plasticity in subjects at risk of developing Alzheimer's disease. Brain. 